DOI: 10.20472/IAC.2017.032.028

\author{
MARTA MATULČÍKOVÁ \\ University of Economics in Bratislava, Slovak Republic \\ DANIELA BREVENÍKOVÁ \\ University of Economics in Bratislava, Slovak Republic
}

\title{
EVALUATION OF EMPLOYEE WORK PERFORMANCE - BASIS FOR IDENTIFYING EDUCATIONAL NEEDS
}

\begin{abstract}
:
Identification of educational needs is the basic starting point of the preparation and planning of corporate education. For the education to be efficient, it is necessary to examine educational needs, based on currently available company information or information acquired for this purpose. In order to identify educational needs properly, it is necessary to conduct the needs analysis on three levels: the enterprise level, job position level, and on the level of individuals. The focus of the paper is on the lowest level, i.e. analysis of individuals, where the process involves the assessment of property traits of individuals, while the decisive factor is the performance and behaviour of employees in the implementation of working activities. The concept of the research is based on the needs of practice and existing legislation in the Slovak Republic. Courses in economics, the aim of which is to develop the knowledge of economics and business skills, are not offered in the study programmes of general medicine, dentistry and biomedical physics to the extent to correspond to the needs for the performance of managerial positions in health establishments or to the performance of private medical practice. The project summarises results acquired during the second year of the work on the project KEGA No. 014EU-4/2016 - "Preparation of the content and structure of subject disciplines focused on the development of knowledge and skills of graduates from non-economic health service fields of study" supported by the government educational agency of the Slovak Republic.
\end{abstract}

\section{Keywords:}

BARS - Behaviourally anchored rating scales, employee evaluation, critical incidents appraisal, social behaviour, work performance, work behaviour

JEL Classification: M53, 120, J20 


\section{Introduction}

Employee work performance has been and is going to be in the future the main sense of personnel work. A traditional approach to human resource management emphasizes work specialization, precisely defined assignments and procedures clearly linked to defined jobs. An employee is an object of managing and decision making; the basis is a directive approach to employees, who receive orders that they are required to perform. Employee work tasks are based on precisely specified performances; however, it is clearly made known to employees, that a desirable performance is that achieved by top employees. This approach is based on the assumption that all employees have equal capabilities for the work performance, while individual factors which determine personality characteristics of an individual are not considered. That may be subsequently reflected in negative impacts on physical and mental health; dissatisfaction with the work performed in the organization is rising, and it is followed by employee de-motivation. On the other hand, individuals who are above the standard achievers are not too stimulated to this kind of performance; the employer is, in essence, satisfied with the standard derived from the average employees' performance. This results in neglecting the abilities of above average and top employees; moreover, there is little space for applying employee creativity.

In human resource management, there is a widespread belief that precisely defined work positions, with long-term defined tasks and obligations are a brake to flexibility and readiness for changes, and it is necessary to replace them with a more dynamic system based on the description of work roles. The role characterizes specific forms of behaviour required for the performance of a particular task or groups of tasks given by the job. Work role defines requirements of how the work is performed rather than in terms of tasks themselves. It can refer to a broad scale of behaviour characteristics, as for instance approach to work, cooperation with other individuals, etc. In the case of the work role, the intention is not only a precise implementation of the task assigned, but its implementation on the basis of one's own perception and in relation to the context, in which they work and with regard mutual operation and relationships with others. Profile (characteristic) of the role does not list tasks; instead it states expectations in the form of results and outputs. It also mentions requirements placed on the abilities in the form of knowledge skills, and experience, needed for the fulfilment of expected outputs and results.

Managing the work performance stands for the fulfilment of the agreement based on the improvement of individual work performance and continuous acquisition of knowledge, skills, and abilities needed for the achievement of anticipated work performance. The evaluation of work performance is a basis for identifying educational needs, which is the subject-matter of exploration of the second stage of the work on the research project KEGA No. 014EU-4/2016 entitled "Preparation of the content and structure of subject disciplines focused on the development of knowledge and skills of graduates from non-economic health service fields of study" supported by the educational agency of the Slovak government.

The paper is a presentation of partial results of the project, which deals with methods of employee evaluation; the methods applied are based on the empirical research, and that in turn served as the basis for identifying educational needs. 


\section{Work Performance and Methods Applied in Employee Evaluation}

Work performance relates to the degree of fulfilment of tasks that create the work content of a particular employee, i.e. how the employee fulfils tasks and requirements of their jobs, or a role, i.e. what are its work behaviour, what are their relationships to co-workers, to customers, and other persons, whom they encounter in the work performance. It means that the subject of evaluation is not only the quantity and quality of work, but also willingness, approach to work, work behaviour, frequency of work accidents, fluctuation, absence, late attendance, relationships to people in connection with the work performed.

Work performance is a result of merging and mutual ratio of effort, abilities, and role perception (perceiving assignments). Evaluation of work performance has to be connected with the presentation of detected results and with negotiation of these results as well as searching for the ways for improving work performance by implementing measures, which are expected to support achieving required results.

Educational needs are determined as the difference between anticipated and actual results of an enterprise between achieved results of individual intra-enterprise departments/units, performance level of individual employees, or other criteria of employee characteristic (Ferjenčík, Bosáková, 2001, p.119). Identification of educational needs ensues from the three-level analysis:

- Organisational level of analysis, the aim of which is to ensure and arrange an efficient running of an organisation in terms of performance, costs and benefits, and organizational culture.

- Knowledge - skill - ability level, which represents the level which determines what abilities, skills, and knowledge are desirable and needed at individual job positions. It is a stock-taking of work assignments and needs of work in an organisation.

- Personal analysis level assesses individual characteristics. It is often used in identifying differences between the actual and required employee's behaviour (Luptáková, Vargic, 2003, p. 8).

For education to be successful and effective, it is necessary to monitor an overall enterprise strategy and enterprise objectives (Vodák, 2006). The rise of educational needs results from the external organisation's environment changes (e.g. change in legislation, new competition, change in technologies, and the like) and from the changes in internal environment of an organization, organizational structure, change in strategy, etc.). (Bartoňková, 2010).

This paper deals with a personal level of analysis. The basis is methods of employee performance evaluation. Here are a lot of methods of employee evaluation (appraisal), and the number of their variants is even higher; however, only some of them will be discussed in the present paper.

Employee performance can be evaluated based on adequate criteria related to work requirements and objectives of work activity, namely work tasks, work conditions, positions of employees in the organisation's arrangement, as well as to anticipated employee behaviour and results achieved at work.

Selected criteria of employee performance evaluation include for example: 
- Knowledge, skills, needs, and properties: knowledge of work, physical forces/powers, ability to coordinate activities, entrepreneurial spirit, ambitiousness, social needs, independence, adjustability, reliability, organizational behaviour, verbal abilities, knowledge of languages, loyalty, honesty, creativity, ability of leading people, sense of complete responsibility, and the like. (Štikař, 2003)

- Professional aptitude: professional knowledge, skills, language proficiency, diplomas and certificates documenting the level of education completed (Trexima, Bratislava Available at www.istp.sk).

- Outputs: number of products made, product quality, rate of defective products, sale of products and services, customer satisfaction, number of claims, and rate of accidents.

- Behaviour evaluation involves:

- Work behaviour refers to willingness to accept tasks, efforts for task fulfilment, work activity, adhering to work procedures stipulated, observing work regime, adhering to regulations, announcing problems, economical approach, handling of equipment, conducting necessary documents, and submitting rationalisation proposals.

- Social behaviour covers willingness to cooperate, the way of treating people, relationships with co-workers, behaviour towards superiors, behaviour towards subordinates, behaviour in public spaces, relationships to customers (Szarková, 2004).

Having specified decisive criteria for the evaluation of employees, we need to deal with employee evaluation methods. Since there are several methods of this kind (Koubek, 2015), we focus only on those identified by respondents in the empirical part of research as the methods utilised in analyzed employer entities.

\section{- Evaluation based on objectives set forth:}

When applying evaluation based on the objectives set forth, employees together with their superior cooperate on defining future work objectives. These objectives should be closely defined, containing terms and deadlines, and mutually accepted and approved. At the same time, it is necessary to agree on the way of fulfilling objectives and create suitable conditions for this purpose. The evaluation is based on a joint assessment to what extent the objectives have been fulfilled. The success of this method rests in the right choice of objectives. If the suitable inspiring objectives are selected, this procedure can favourably influence the employee motivation and likewise increase the work productivity. On the other hand, there may arise also some problems, which could be avoided by a continuous monitoring and evaluation of achieving objectives.

- Evaluation based on the rating scale: The method of evaluation by means of rating scale belongs to the most widespread methods.

- When applying the method, the result of evaluation is expressed in marks, points, expressing agreement or disagreement with some sign/character, graphical expression, and the like. Advantages of this kind of evaluation are its many-sided applicability, operative, simple, and comprehensible nature; Moreover, it is not time consuming; it does not usually require special training of evaluators, and it can be applied also in evaluating a higher number of employees. 
- Individual aspects of work are evaluated separately (e.g. the amount of work, work quality, presence at work, independence, precision, willingness to cooperate, knowledge of work, and the like.)

- The following three rating scales are applied:

- numerical,

- graphical,

- verbal.

- Numerical scale - each criterion is rated by means of numerical values (points) and the importance of individual criteria may be differentiated by means of differing point scale, various point values, or various weights used for the calculation of average grade point.

- Graphical scale - the evaluation of each criterion is marked on an abscissa. A summary appraisal is expressed by a curve connecting points marked on separate abscissas.

- Verbal scale - the performance level is evaluated either by a relevant word for each criterion; alternatively, a graded verbal description of situation is provided, or a description of an employee performance.

A disadvantage of the method is that some evaluators need not be able to understand the verbal description or may interpret it in the same way, which is the result of differing experience or education or an evaluator's personality.

\section{- Behaviour checklist}

Checklist is a questionnaire which contains various statements concerning an employee's work performance, and the evaluator marks if some type of behaviour is present or not in the employee's performance (yes or no). Answers are evaluated by a specialist of a personnel department/unit, and separate formulations may be assigned differing values in the evaluation. This method requires a thorough preparation; it is time-consuming, as each group of job positions requires a specific form and specific formulations. The application of this method tends to be loaded with the evaluator's biased attitude and queries may be interpreted by different evaluators in a different way.

\section{- Behaviourally Anchored Rating Scales - BARS method:}

Method that is to evaluate the behaviour required for a successful work performance. BARS method is some variant of the checklist and assessment scale. It is based on the assumption that a desirable work behaviour results also in an effective work performance. Scales are processed for each assignment performed at workplace: work behaviour is rated in the range from 1 to 7 scoring system (e.g. 7 - excellent, 6 - very good, 5 - good, 4 - average, 3 - below average, 2 - poor, and 1 - unacceptable). The evaluator based on the pattern characteristic of behaviour indicates a corresponding level of behaviour for an evaluated employee.

- Result of evaluation may be expressed as the sum of point values for all the assignments or a combination, or an average of achieved point values.

- Classification scales are as a rule prepared by executive employees together with persons allocated to job positions.

- It is suitable to adhere to the following procedure:

- Individual tasks are identified and defined.

- Descriptions of possible work behaviour are provided for each type of job position.

- Based on the accord of managers and workers, there will be elaborated a scale corresponding to the type of work behaviour supplemented with sample descriptions of work behaviour.

- Compiling rating scales, which anchor behaviour, is rather difficult in terms of their content, but also from the aspects of time and finance. 
The advantage of this method lies in the fact that employees themselves participate as early as in the preparatory stage, which increases the probability that the evaluation will be accepted by employees.

\section{- Critical incidents and key events method:}

This method assumes the characteristic of the so-called threshold events in an employee behaviour, this means exceptionally productive or exceptionally unproductive behaviour, with regard to some of the employee's work positions. During the period evaluated the line manager concerned records (briefly describes) these key events, caused by their subordinates. At the same time, these events are classified into two groups (positive and negative behaviour). The key events method may be efficient mainly as a result of underestimating current records of individual events and sometimes also due to their misunderstanding and interpretation.

At the centre of educational needs analysis is a person who performs the job himself/herself. When evaluating employee work performance for the purposes of identifying educational needs, we can usually encounter with the following three areas of evaluation:

- Work performance evaluation

- Employee development evaluation

- Relationship evaluation

so that we were able to adjust the content of education to educational needs of employees.

\section{Methodological Starting Points of Empirical Research}

To prepare a tailor-made education for each employee requires a thorough analysis of an employee performance as well as that of requirements placed on the workforce in job positions. In empirical research, the focus is on respondent opinions, data collection, analysis of requirements on the performance of individual work activities and on methods of work performance evaluation. As the research was extensive, and in the present paper we present only some results on the application of employee performance evaluation methods as the background for the identification of educational needs.

Respondents were selected on a random basis, while they had to fulfil the following specific criteria:

- Completed education: complete secondary education finished with maturita examination (comparable to GCSE) and university education;

- Type of activity performed:

- Technical jobs, including: auxiliary and preparatory work; service jobs; routine jobs; specialised jobs; systemic tasks/jobs.

- Creative jobs

- Managerial jobs, including those on the levels of line management, middle management and top management; owners in the case of small enterprises.

According to the statistical Classification of economic activities SK NACE Rev. 2, under Decree No. 306/2007 Coll., for the purposes of analysis, human resources in C section of Industrial production were selected from the following twelve divisions: $10-$ Manufacture of foodstuffs; 11 - Manufacture of beverages; 12 - Manufacture of tobacco products; 14 - Manufacture of clothing; 15 - Manufacture of leather and leather articles; 
16 - Wood-processing and production of wood and cork products, except furniture, manufacture of straw and wicker-work articles; 17 - Manufacture of paper and paper products; 20 - Manufacture of chemicals and chemical products; 21 - Manufacture of basic pharmaceutical products and pharmaceutical fixtures; 22 - Manufacture of rubber and plastic products; 29 - Manufacture of motor vehicles, semi-trailers and appendages; and 31 - Manufacture of furniture.

Participants of research were selected from all the three types of enterprise in terms of size, namely:

1. Small enterprise up to 49 employees

2. Medium-sized enterprise up to 249 employees

3. Large enterprise over 250 employees.

The research was conducted by means of the interview method and the questionnaire method. To obtain an insight into respondents' opinions and experience, the interview method was applied. The questionnaire method was used for practical reasons since the research required a representative respondent sample. This method enables a researcher to collect information from a large number of respondents in a relatively short time and at acceptable costs. Primary data were collected by means of an interview, based on the questions in the questionnaire prepared beforehand. The questionnaire consisted from two basic parts, namely the information part including basic data about each respondent and the professional part dealing with the stage of preparation, implementation and further development of respondents' careers, while considering their parents' positions and the level of their completed education. The questionnaires were distributed personally or online.

The number of respondents was calculated based on the number of employees in explored C - section divisions: Industrial production. The relevant data were based on statistics of the year 2012, at $95 \%$ level of reliability calculated, and $6 \%$ tolerance. The sample consisted from 267 respondents, 155 employees in non-managerial positions, and 112 employees in managerial positions. In terms of size, there were 52 respondents from small enterprises, 80 respondents from medium-sized enterprises, and 135 respondents from large enterprises.

Individual employees represent statistical units in the research, and their opinions are considered as the basis for the application of selected statistical methods. This way, we will be able to evaluate the problems analysed. Results of statistical processing are presented via statistical surveys in tables supplemented with verbal interpretation.

\section{Results of Empirical Research}

Employee performance evaluation and the analysis of obstacles to the performance will enable us to become familiar with educational needs. In terms of identifying educational needs, it is necessary to start from investigating contemporary performance, namely by gathering information on performance, describe it, and indicate its level. A step-by-step analytical process should provide an answer to following questions:

- What is the performance required? What are the performance indicators?

- What is the difference between the actual and required performance? 
- What are the obstacles to an effective performance?

It is important to be familiar with obstacles to work performance not only when we are trying to increase the productivity of labour, but also when we need to identify educational needs. Obstacles to effective performance can be classified in four groups, namely human obstacles, technical obstacles, information obstacles, and organizational obstacles:

- Human obstacles include various types of shortage, e.g. lack of knowledge, skills, aptitudes, motivation, or stimulation tools, and informal management.

- Technical obstacles are manifested as poor design of work place, shortage of resources, shortcomings in standardised procedures, and fast technological changes.

- Information obstacles arise as poorly defined objectives, shortcomings in performance measurement, unprocessed data, or inadequate feedback;

- Organizational obstacles cover overlaps of responsibilities and activities, lack of flexibility and mobility, and problems with control system.

When analysing human obstacles, it is necessary to consider various kinds of information, which document and describe the given fact. The following information is available for this purpose in enterprises:

- Currently available information in employer entity (information gained from employee evaluation, from reviews, consultations, discussions, absences, as well as from the evaluation of work time utilisation, etc.);

- Information acquired for a special purpose by means of various methods (interview, observation, questionnaire, work samples, and the like).

When applying the questionnaire method, we explore what methods and how they are applied in an analysed sample of enterprises. Their application is depicted in Table 1.

Tab. 1: Methods applied in employee evaluation based on respondent opinions in $\%$.

\begin{tabular}{|l|l|l|l|l|l|l|}
\hline \multicolumn{1}{|l|}{$\begin{array}{l}\text { Size of } \\
\text { business }\end{array}$} & \multicolumn{2}{l|}{$\begin{array}{l}\text { Small enterprises } \\
52\end{array}$} & \multicolumn{2}{l|}{$\begin{array}{l}\text { Medium-sized } \\
\text { enterprises } \\
80\end{array}$} & \multicolumn{2}{l|}{$\begin{array}{l}\text { Large enterprises } \\
135\end{array}$} \\
\cline { 2 - 7 } \\
$\begin{array}{l}\text { Methods of } \\
\text { evaluation }\end{array}$
\end{tabular}

Source: results of own empirical research 
The table above shows respondents' opinions of the application of evaluation methods used in enterprises in terms of their size. In each enterprise group, the number of respondents was different, as mentioned in the research methodology. Respondents were selected from various enterprises to obtain an idea of methods applied in the evaluation. In separate enterprises, several methods of evaluation could be applied. A prevailing method was selected for each enterprise, i.e. one that achieved the highest modus value. Application of evaluation methods varies in respect of separate groups of employees and separate intra-enterprise units. We have not included employees who perform prevailingly manual working activities. A significant method, i.e. the evaluation based on the standard-fulfilment, therefore does not appear in our research results, nor does the method based on ordering one employee in relation to another by their work performance.

\section{Conclusion}

We can conclude from the conducted research that the larger the enterprise, the more often quantitative characteristics based methods are applied (especially when using rating scales or BARS method), which enables us to evaluate and compare employees. In the cases of evaluation by objectives and checklist, quantification is possible by my means of statistical methods. Quantification is the most difficult in the critical incidents method. The reason is that this method involves description and making records.

The monitoring of actual performance, detecting disproportions in regard of the performance required, and dealing with resulting problems are processes, which require a comprehensive and system approach. This kind of approach is based on carefully gathered data and their subsequent analysis and evaluation. Based on the empirical research, it is possible to propose a procedure that is beneficial for designing educational activities, while considering concrete identified needs of employees and employee groups.

We propose the following sequence of steps:
A. Identification of the problem.
B. Identification of the rate and type of damage or loss incurred to an employer entity (organisation).
C. Identification of causes.
D. Identification of benefits.
E. Implementation of the solution and evaluation.

\section{A. Identification of the problem:}

Identification of the problem involves to determine how the problem is manifested, and what assignments are performed poorly or inadequately. It is necessary to find out the period of the origin of problem and describe its development or changes. It is also established to what extent the problem is general or specific. If it is specific, we have to decide if it appears in all similar work groups, when it appears - connection with time, management style, and the like; or if the problem is specific for individual employees monitored. It is also suitable to explore experience with solving similar problems in the past. 


\section{B. Identification of the rate and type of loss incurred to the employer entity (organisation):}

Decrease in work performance is reflected in results of work in the entire employer entity. In this context, we need to identify the number of employees who do not achieve the performance required and quantify costs of non-fulfilment performance criteria. These costs on the one hand, include direct financial costs, connected with the decrease in incomes, on the other hand, they involve mediation costs manifested as lower work moral, breach of safety measures, and damaging the name and reputation of the entity.

\section{Identification of causes:}

Causes of problems can be summarized in two basic groups:

I. Causes resulting from environment

II. Causes related to knowledge and skills

Tab. 2 Causes of work performance problems

\begin{tabular}{|l|l|}
\hline $\begin{array}{l}\text { I. Causes resulting from environment } \\
\text { (expert's task is advisory) }\end{array}$ & $\begin{array}{l}\text { A. Interference of tasks } \\
\text { B. Inadequate feedback } \\
\text { C. Inadequate consequences }\end{array}$ \\
\hline & $\begin{array}{l}\text { A. Identify areas (knowledge, skills, } \\
\text { abilities, and attitudes), in which the } \\
\text { level does not correspond to standards } \\
\text { required. } \\
\text { B. Indicate and specify shortages in } \\
\text { competences. Competence is a set of } \\
\text { ways of behaviour and action of an } \\
\text { employee, which has to be used in } \\
\text { a given position so that the task could } \\
\text { be competently mastered. The basis is } \\
\text { a competence model, which is a way } \\
\text { leading to managing diversity and } \\
\text { performance rather than that of } \\
\text { creating a standard,. } \\
\text { C. Reveal problems in obtaining and } \\
\text { gaining and acquiring knowledge, } \\
\text { skills, and abilities, and explore the } \\
\text { possibilities and conditions of } \\
\text { application. }\end{array}$ \\
\hline
\end{tabular}

Source: results of empirical research and study of literary sources

\section{Identification of benefits}

Benefits analysis involves the analysis of benefits and losses, which has to be conducted immediately after the decision that the work performance can be improved by means of education. On the one hand, we have to add up the costs of implementation of education, i.e. costs of project design, costs of participants (travel costs connected with replacing and substituting employees absent because of their participation in the educational activity, etc.), costs of lectors and educational facility have to be calculated, as well as the loss of profits. It is desirable to consider also the interference with the work continuity at workplace, employee moral, safety or possible health risks. The benefits constitute an increase in work performance. However, we need to consider the 
financial advantages we could gain in case we do not organise employee education and training; that is, if searching for more simple solutions is not a more advantageous option.

\section{E. Implementation of the solution and evaluation}

At this stage, it is important to cooperate with management, or at least with human resource management, in order to implement the best solution. If an educational programme is extensive and too costly, it is suitable to set up a pilot group and start with the implementation in the broad extent variant only after the assessment of results achieved and after identifying possible shortcomings.

When analyzing employee work performance to identify needs for education, it is necessary to evaluate the extent to which we are able settle the differences between the actual and required performance by education, and determine whether we could achieve that faster, at higher quality, or more effectively.

\section{Reference}

BARTOŇKOVÁ, H.: Firemní vzdělávaní. Strategický přsstup ke vzdělávani pracovnikủ. The First Edition. Praha : Grada Publishing, a. s. 2010.

FERJENČík, J., BOSÁKOVÁ, M.: Riadenie ludských zdrojov. Bratislava : Publishing House Ekonom, 2001.

LUPTÁKOVÁ, S., VARGIC, B.: Performance Appraisal as a Part of Managerial Work in Slovak Organizations. In: The Seventh International Conference on Global Business and Economic Development, Bangkok, 2003, p. 8.

TREXIMA, s.r.o., Bratislava. Available at www.istp.sk.

KOUBEK, J.: Řizení lidských zdrojů. Základy moderni personalistiky. Praha : Management Press, 2015, 219pp.

ŠTIKAŘ, J., RYMEŠ, M., RIEGEL, K., HOSKOVEC, J.: Psychologie ve světe práce. Praha : Nakladatelství Karolinum, 2003.

SZARKOVÁ, M.: Psychológia. Základy ekonomickej psychológie. Bratislava : Vydavatelstvo Ekonóm, 2004.

VODÁK, J.: Proces identifikácie potrieb vzdelávania v manažérskej praxi. In Kvalita a zodpovednost' č. 2/2006, roč. 14 , s. 34. 